\title{
Draft Theory in Japan
}

\author{
By Kiyohisa Fujino \\ Chairman, Draft Research Committee, TMSJ \\ Faculty of Engineering, Kyoto University
}

Drafting, doubling, twisting and winding are the basic elements of the spinning procedure. It is common knowledge that drafting is a process to draw a fiber bundle and make the fiber bundle finer. Unlike the other elements, drafting is undertaken at almost every stage of the spinning process which converts fiber material into spun yarn; and drafting at each stage influences the evenness of the produced fiber bundle to such an extent as to have a direct bearing on the quality of the final product of the spinning process, i.e., spun yarn. It is not surprising, then, that drafting has prompted strenuous researches in recent years.

It is a long time since Vasilieff published his theory in 1915. Remarkable progress has been made in the draft theory in the last few years, and it now ranks foremost in theories concerning textile technology.

Generally, one of the important requirements for the satisfactory quality of spun yarn is the evenness of yarn thickness. However, fibers, the constructive elements of yarn, are always short and irregular in length and also uneven in thickness. Such fibers make yarnirregularity unavoidable, because even if the front ends or middle points of the fibers are uniformly distributed along the yarn axis, the number of fibers in any yarn-section or yarn thickness is hardly even.

It is, therefore, important to minimize such irregularity of the fiber bundle in the spinning process. This problem can be divided into three points. The first point is to improve the draft theory so as to establish a theoretical foundation for the drafting mechanism.

The second point is to improve the drafting device which is connected directly with the generation of yarn irregularity. The optimum condition for improving the drafting device and suitable mechan'sm to minimize the yarn irregularity should be found out.

The third point is to make clear the characteristics of irregularity of yarn, sliver, roving as such fiber fundle, to analyze the effects of the drafting process and to evaluate the quality of the produced spun yarn.

Thus, a research on drafting should consist of three branches: theoretical research on the drafting process, experimental research on drafting devices and analysis of yarnirregularity.

In what follows is presented a brief history of researches made in Japan on the drafting theory.

Theoretical inquiry into draft, especially into the behaviors of fibers in the draft zone and irreguarity of the poduced fiber bundle, was begun in 1944. Since then, many papers have been published in Japan by the authors whose names are listed in the table. Some of the authors have been influenced by foreign publications, The others have developed theories of their own.

A geometrical analysis of the distribution and movement of fibers in the draft zone was made by $S$. Ishikawa in 1944. Since then, investigation in th $\mathrm{s}$ field has made steady progress. Above all, the fiber arrangement in the draft zone and the irregularity of the produced fiber bundle have been chosen by a host of authors as a subject fior study.

Fiber arrangement was statistically discusseed by $Y$. Narita [1] in 1948 and looked into by A. Ikeda [1] in 1951-52. A. Ikeda and $R$. Kinoshita [2] made their investigations into the mechanism of the draft-wave and deduced a functional equation of the wave-amplitue.

M. Tabata, S. Ishikawa [1],T. Ichino and H. Goto [1] treated the subject of fiber arrangement dynamically and found the average of the fiber distribution in the draft zone. They endeavored to clarify sliver irregularity analytically but failed to find its general solut on. In $1948 \mathrm{~S}$. Watanabe [3] announced the so-called diagram which represents geometrically the relation between fiber length and the number of fibers along an idealized sliver axis. It was found that the diagram was broadly applicable to the analysis of fiber arrangement, sliver irregularity, etc.

M. Matsuzaki[1] made a study on drafting in cotton spinning and found that card sliver had the most regular arrangement, which howetver, deterjorated gradually in the subsequent processes.

In $1948 \mathrm{Y}$. Narita [1] inquired into the effect of doubling. He pursued h"s inquiry in 1951 by studying with $\mathrm{T}$. Uchida and $\mathrm{K}$. Mihira the influences of draft and doubling upon sliver irregularity.

In 1952-53 K. Fujino and A. Horikawa [4] made some researchs on sliver irregularity caused by mechanical defects of the rollerdraft device.

In $1955 \mathrm{~T}$. Yamagishi, H. Furuyama and H. Kuroe [5] jointly made a stuly on sliver irregularity under a condition in which the 
surface velocity of the front roller was varied.

\begin{tabular}{|c|c|c|c|c|}
\hline \multirow[b]{2}{*}{$\begin{array}{l}\text { Date } \\
\text { published }\end{array}$} & \multicolumn{2}{|c|}{ Researches abroad } & \multicolumn{2}{|c|}{ Researches in Japan } \\
\hline & Author & $\begin{array}{l}\text { Classifi- } \\
\text { cation }\end{array}$ & Author & $\begin{array}{l}\text { Classifi- } \\
\text { cation }\end{array}$ \\
\hline 1915 & Vasilieff & $\mathrm{D}, \mathrm{b}$ & & \\
\hline 1928 & Balls & $\mathrm{A}, \mathrm{b}$ & & \\
\hline 1031 & Goodings & $\mathrm{A}, \mathrm{b}$ & & \\
\hline 1944 & & & Ishikawa & $\mathrm{B}, \mathrm{a}$ \\
\hline 1948 & $\operatorname{Cox}$ & $c, a, b$ & Watanabe & $\mathrm{B}, \mathrm{a}, \mathrm{b}$ \\
\hline & Cox, Ingham & $\mathrm{E}, \mathrm{D}, \mathrm{b}$ & Narita & $\mathrm{D}, \mathrm{a}, \mathrm{b}$ \\
\hline 1950 & Hannah & C, a,d & Uchida,Mihira & $\mathrm{C}, \mathrm{b}$ \\
\hline & Foster & $\mathrm{C}, \mathrm{b}$ & & \\
\hline 1951 & $\begin{array}{l}\text { Gregory, Tyson } \\
\text { Cocke }\end{array}$ & $\begin{array}{l}\mathrm{B}, \mathrm{C} \\
\mathrm{B}, \mathrm{b}\end{array}$ & Ikeda & $\mathrm{B}, \mathrm{a}$ \\
\hline 1952 & $\begin{array}{l}\text { Foster } \\
\text { Green, Ingham } \\
\text { Foster }\end{array}$ & $\begin{array}{l}\text { A, B, b, c } \\
\text { B, a, d } \\
\text { B, C, c }\end{array}$ & & \\
\hline 1953 & Hannah & $\mathrm{D}, \mathrm{g}$ & $\left\{\begin{array}{l}\text { Fujino } \\
\text { Harikawa }\end{array}\right.$ & $\mathrm{C}, \mathrm{c}$ \\
\hline & Cox & $\mathrm{D}, \mathrm{g}$ & & \\
\hline 1954 & Grishiu & $\mathrm{D}, \mathrm{b}$ & $\left\{\begin{array}{l}\text { Tabata } \\
\text { Ishikawa }\end{array}\right.$ & $\mathrm{C}, \mathrm{a}, \mathrm{b}$ \\
\hline & & & Ichine, Goto & $\mathrm{C}, \mathrm{a}, \mathrm{b}$ \\
\hline & & & $\begin{array}{l}\text { \{Tabata } \\
\text { Ishikawa } \\
\text { Yamag shi }\end{array}$ & $\mathrm{B}, \mathrm{b}$ \\
\hline 1955 & Grosberg & $\mathrm{B}, \mathrm{b}$ & $\left\{\begin{array}{l}\text { Furuyama } \\
\text { Kuroe }\end{array}\right.$ & $\mathrm{C}, \mathrm{c}$ \\
\hline & & & $\left\{\begin{array}{l}\text { Ikeda } \\
\text { Knoshita }\end{array}\right.$ & $\mathrm{B}, \mathrm{a}, \mathrm{b}$ \\
\hline 1956 & Foster, Tyson & $\mathrm{B}, \mathrm{c}$ & $\begin{array}{l}\text { Mihira } \\
\text { (Tabata }\end{array}$ & $\mathrm{D}, \mathrm{a}, \mathrm{b}$ \\
\hline 1957 & & & $\left\{\begin{array}{l}\text { Ishikawa } \\
\text { Mihira }\end{array}\right.$ & $\mathrm{D}, \mathrm{b}$ \\
\hline
\end{tabular}

Founamental base:

A: Intuitive

B: Geometrical

C: Dynamical or statical

D: Statistical

Subject of study:

a: Fiber arrangement in the draft zone, etc.

b: Irregularity due to drafting and doubling

c: Irregularity due to mechanical failure

d: Optimum conditions

e: Behavior of fibers

f: Draft force

$\mathrm{g}$ : Irreyularity due to fiber blending
S. Ishikawa and M. Tabata [1] represented fiber behavior in the draft zone by means of distributions of speed-change points and statistically calculated the variation of the number of fiber front ends existing in any limited sliver length. Periodical variations of nip points and those of the weight of a sliver length were also found.

Through all these researches, probes have been made into draft irregularity caused by variation of the speed-change points, the uneven movement of the fiber bundle, the breakoff of sliver, the defect of the drafting devices and the irregularity of the supplied slivers, and a generalized draft theory has been established.

On the other hand draft cut spinning, a subject on which there are only a few published works abroad, has prompted strenuous researches and a crop of treatises on drafting devices and sliver irregular'ty is found in Japanese journals. A review of these treatises will be made at a future date.

About four years ago The Textile $\mathrm{Ma}-$ chinery Society of Japan organized a Draft Research Committee, an intra-Society organ. It has the active cooperation of some of the authors referred to in this article. They still continue their work in this field.

\section{References}

[1] Published in the Journal of Textile and Cellulose Industries, Japan and other Japanese journal

[2] A. Ikeda and R. Kinoshita; On a Staple Diagram and the Roller Draft, J. Text. Mach. Soc., Japanese edition, Vol. 8, No. 7, p. 495 (July 1955)

[3] S. Watanabe; Theory of Drafting in Spinning Process, J. Text. Ma,ch. Soc., Japanese edition, Vol. 1, No. 12 , p. 5 (Dec. 1948)

[4] K. Fujino and A. Horikawa; Study on the Roller Draft. Part $1 \sim 3$, J. Text. Mach. Soc., Japanese edition, Vol. 5, No. 11, p. 2 (Nov. 1952)-Vol. 6, No. 1 , p. 2 (Jan. 1953)

[5] T. Yamagishi, H. Furuyama and H. Kuroe; A Theoretical Study of Roller Draft, J. Text. Mach, Soc., Japanese edition, Vol. 8, No. 8, p. 521 (Aug. 1955) 